\title{
The Historiography of Medieval Portugal, c.
} 1950-2010

José Mattoso, dir., Lisboa, Instituto de Estudos Medievais, 2012

Jaume Aurell

\section{(2) OpenEdition \\ Journals}

Edição electrónica

URL: http://journals.openedition.org/medievalista/536

DOI: 10.4000/medievalista.536

ISSN: 1646-740X

\section{Editora}

Instituto de Estudos Medievais - FCSH-UNL

\section{Refêrencia eletrónica}

Jaume Aurell, «The Historiography of Medieval Portugal, c. 1950-2010 », Medievalista [Online],

13 | 2013, posto online no dia 19 fevereiro 2014, consultado no dia 30 abril 2019. URL : http:// journals.openedition.org/medievalista/536 ; DOI : 10.4000/medievalista.536

(C) IEM 
Título: The Historiography of Medieval Portugal, c. 1950-2010. (José Mattoso, dir., Lisboa, Instituto de Estudos Medievais, 2012)

Autor(es): Jaume Aurell

Enquadramento Institucional: Depart. Historia, Universidad de Navarra, Navarra, España Contacto: saurell@unav.es

Fonte: Medievalista [Em linha]. №13, (Janeiro - Junho 2013). Dir. José Mattoso. Lisboa: IEM.

Disponível em: http://www2.fcsh.unl.pt/iem/medievalista/ ISSN: 1646-740X

\section{The Historiography of Medieval Portugal, c. 1950-2010}

(José Mattoso, dir., Lisboa, Instituto de Estudos Medievais, 2012)

\section{Jaume Aurell}

Este libro proporciona un documentado, sistemático, riguroso, exhaustivo y útil "estado de la cuestión" de los estudios medievales en Portugal durante la segunda mitad del siglo XX y principios del siglo XXI. Promovido por el "Instituto de Estudos Medievais" 
de la Universidade Nova de Lisboa, el volumen, de autoría colectiva, analiza exhaustivamente las diferentes temáticas y metodologías desarrolladas por los medievalistas portugueses en los últimos sesenta años.

La estructura de la obra está claramente dominada por las cuestiones temáticas más que por las tendencias metodológicas o epistemológicas. Después de una concisa pero elegante nota editorial de los editores, en la que se explican los criterios básicos de la construcción del libro, aparece una sintética introducción firmada por José Mattoso, en la que se dibujan las principales tendencias y aportaciones de los estudios medievales en Portugal desde la segunda guerra mundial. Siguen después cuatro contribuciones relacionadas con el campo de los estudios literarios: las ediciones documentales (Saul António Gomes), el trabajo sobre los manuscritos (Maria do Rosário Barbosa Morujão), los estudios latino-portugueses (Paulo Farmhouse Alberto, Rodrigo Furtado, Ana Maria Martins), y el estudio de los textos literarios medievales (Teresa Amado). Las dos siguientes están dedicados a la historia del arte medieval (Maria Leonor Botelho), una de ellas específicamente a la música (Manuel Pedro Ferreira). El siguiente capítulo está dedicado a los estudios arqueológicos del Portugal islámico y cristiano (Isabel Cristina Ferreira Fernandes, Santiago Macias). El plan continúa con tres contribuciones sobre los estudios políticos, desde el punto de vista institucional (Armando Luís de Carvalho Homem), municipal (Maria Helena da Cruz Coelho), y de las relaciones diplomáticas (Maria João Branco, Mário Farelo). Se acometen después tres temas relacionados con las cuestiones socioeconómicas: la economía y la fiscalidad (Felipe Themudo Barata, António Castro Henriques); la historia urbana (Amélia Aguiar Andrade, Adelaide Millán da Costa) y la historia rural (Luís Carlos Amaral); la Iglesia y la religiosidad (Hermínia Vasconcelos Vilar, Maria de Lurdes Rosa); la historia intelectual (José Francisco Merinhos); el estudio de la historiografía (António Resende de Oliveira); la historia nobiliaria (José Mattoso); la historia de las órdenes militares (Luís Filipe Oliveria et alt.); la historia militar (Miguel Gomes Martins, João Gouveia Monteiro); la historia de las mujeres y la historia de género (Manuel Santos Silva, Ana Maria S.A. Rodrigues); la historia "en los márgenes" de la sociedad (Luís Miguel Duarte) y la historia de la vida cotidiana (Manuel Sílvio Alves Conde). Dos de los últimos capítulos están dominado por una aproximación más cronológica que temática: los estudios sobre la antigüedad tardía y la temprana edad media (Manuel Justino Maciel) y el estado de la 
cuestión entorno a la fase de los primeros descubrimientos y expansión portuguesa allende los mares (João Paulo Oliveira e Costa). Siguen después dos capítulos dedicados a las minorías étnicas y religiosas (Hermenegildo Fernandez y António Rei sobre los mozárabes y Maria Filomena Lopes de Barros para otras minorías como los judíos), que conducen al capítulo conclusivo, una bien documentada síntesis, en la que Judite A. Gonçalves de Freitas realiza un análisis de la evolución de los estudios medievales portugueses durante el siglo XX.

La variedad y exhaustividad de los temas tratados constituyen por sí mismas un testimonio de la utilidad de este volumen, no sólo para los medievalistas portugueses o, en general, para los interesados en la historia medieval de Portugal, sino también para los académicos provenientes de otras tradiciones. Los autores son medievalistas procedentes de las más diversas disciplinas (historia, historia del arte, arqueología, crítica literaria, lingüística y filosofía, entre otras) lo que dota a la obra de una enorme energía disciplinar. La gran mayoría de los autores son portugueses y, por tanto, familiarizados de modo natural con la evolución de la historiografía de su país. En este sentido, se echa en falta quizás alguna contribución más realizada por algún medievalista familiarizado con la historia de Portugal pero no necesariamente inmerso en ese ámbito del medievalismo, para dotar a la obra de una mayor perspectiva, siempre necesaria en este tipo de estudios.

Cada contribución contiene un gran número de detalles y de información bibliográfica que convierten a la obra en un indispensable instrumento para todos aquellos que se inician, o quieren profundizar, en alguno de los aspectos que se detallan. Las notas a pie de página son suculentas y exhaustivas, y algunas de ellas constituyen auténticos “estados de la cuestión” de algún aspecto histórico concreto, o del desarrollo de algunos debates en torno a alguna cuestión determinada.

Quizás la mayor objeción que se pueda hacer al volumen es la falta de algunos artículos que sinteticen la información, o la hagan más cohesiva, y que la pongan en contexto con las líneas maestras del pensamiento histórico y las tendencias intelectuales de Portugal durante el período escogido (1950-2010), así como con las tendencias historiográficas y literarias internacionales. El artículo de Judite A. Gonçalves de Freitas - quien reconoce en la primera nota la colaboración de Maria de Lurdes Rosa en la elaboración del 
artículo - es, desde luego, un primer acercamiento a esta aproximación global. Titulado "Syntheses, Guides and States of the Art", es un magnífico recorrido la evolución del medievalismo portugués durante el siglo XX. Pero ese artículo quizás podría haberse complementado también por otros firmados por contemporaneistas, especialistas en historiografía, que situaran al medievalismo portugués en el contexto de las tendencias generales del medievalismo internacional, y de la propia evolución intelectual del Portugal del siglo XX.

El volumen constituye una extraordinaria aportación para el conocimiento de los logros del medievalismo portugués del siglo XX, aunque quizás se pueda complementar en el futuro con esta información más propiamente de historia intelectual y académica. También es cierto que al regirse la obra por un criterio temático más que metodológico o de tendencias historiográficas, esta visión más global es difícil de conseguir. Y estoy seguro que, después de haber acometido este esfuerzo hercúleo, los editores de la obra (Maria de Lurdes Rosa, Bernardo Vasconcelos e Sousa y Maria João Branco) encontrarán en el futuro alguna posibilidad de realizar este análisis de corte más teóricohistoriográfico, en el que muestren los paralelismos, las concordancias o discordancias cronológicas o epistemológicas entre el medievalismo portugués y el medievalismo europeo e internacional, acometiendo algunas preguntas: ¿hasta qué punto los paradigmas historiográficos de la posguerra (estructuralismo, marxismo, cuantitativismo) encontraron eco en el medievalismo portugués? ¿cómo han influido en el medievalismo portugués las tendencias recientes, provenientes más bien de los Estados Unidos, como el Nuevo Medievalismo, la nueva historia cultural, o la Nueva Filología, que han afectado tanto a los estudios históricos como a los literarios? ¿hasta qué punto se han producido encuentros disciplinares entre la historia, la crítica literaria y la filosofía, por un lado, y la antropología y otras ciencias sociales por otro? Son estas cuestiones, y muchas otras, que aparecen ya de hecho respondidas a nivel de detalle en algunas de las contribuciones, pero no desde una perspectiva global.

Se pueden reseñar también otros pequeños detalles. La cronología utilizada es muy coherente, pues la segunda guerra mundial supone una ruptura de las tendencias académicas e historiográficas evidente, y los editores han tenido el valor de pedir a los autores que se adentren en las tendencias más recientes. Más discutible es, sin embargo, la decisión de no realizar un "índice de nombres", que suele ser una herramienta 
indispensable para este tipo de estados de la cuestión. Con el índice de nombres (que se podría incorporar si se realiza una nueva edición de la obra) se podrían cotejar las diferentes contribuciones y tener una visión más comparativa e integrada, al localizar el nombre de medievalistas que hayan estado vinculados a diversas áreas o tendencias.

En todo caso, se trata de un proyecto de proporciones hercúleas (un adjetivo que ya he utilizado antes de forma deliberada), que ciertamente, como a todos los proyectos tan ambiciosos, se le pueden encontrar algunas carencias, pero que quedará ya como un informe indispensable sobre el estado del medievalismo portugués durante la segunda mitad del siglo pasado. Y, sin duda, es una muestra más de la creciente vitalidad que el medievalismo portugués está mostrando en las épocas más recientes, bien fundamentado en la base erudita que legaron sus fundadores. Finalmente, tal como reconocen los propios editores, la suya es una aportación académica realmente relevante, "difficult but rewarding". 


\section{COMO CITAR ESTE ARTIGO}

\section{Referência electrónica:}

AURELL Jaume - “The Historiography of Medieval Portugal, c. 1950-2010”.

Medievalista [Em linha]. №13, (Janeiro - Junho 2013). [Consultado dd.mm.aaaa].

Disponível em

http://www2.fcsh.unl.pt/iem/medievalista/MEDIEVALISTA13/aurell1302.html.

ISSN 1646-740X.

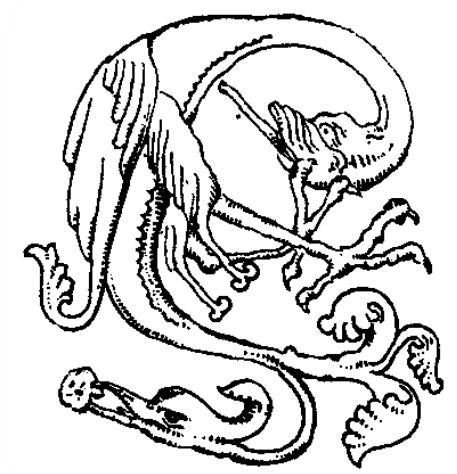

Medievalista online $\mathrm{N}^{\circ} 13$ | Janeiro - Junho 2013 @ IEM - Instituto de Estudos Medievais 6 www2.fcsh.unl.pt/iem/medievalista 